\title{
CONFERÊNCIAS NACIONAIS DE SAÚDE: GANHOS DEMOCRÁTICOS OU REPRODUÇÃO DA NOSSA CULTURA POLÍTICA?
}

Tânia Regina Krüger ${ }^{1}$

\section{RESUMO}

Este texto apresenta e analisa os resultados de uma pesquisa realizada na $12^{\mathrm{a}}$ Conferência Nacional de Saúde, em 2003, com objetivo de conhecer os pontos positivos e negativos que os seus participantes identificaram na realização destas plenárias. As Conferências de Saúde vêm sendo reconhecidas como amplos espaços de democratização do setor saúde, tendo em vista seu papel de avaliar e fazer proposições para efetivação da política de saúde. Nestas duas décadas de vida do SUS as Conferências de Saúde estão formalmente representando uma socialização do debate político e estão abrindo canais à participação para segmentos sociais antes excluídos do debate sobre as decisões públicas e governamentais. No entanto, os resultados deste estudo apontam que estes ganhos são parciais e contraditórios.

PALAVRAS-CHAVE: SUS; Conferência de Saúde; Controle Social e Socialização da política.

\section{INTRODUÇÃO}

As Conferências de Saúde no Brasil acontecem desde 1941, mas apenas com a $8^{\mathrm{a}}$ em 1986 vem sendo reconhecidas como amplos espaços de democratização do setor saúde, tendo em vista seu papel de avaliar e fazer proposições para efetivação da política de saúde. Se inicialmente as Conferências eram abertas a gestores, representantes do setor previdenciário e privado em saúde, com o processo de Reforma Sanitária, vivido nos anos de 1970-80, elas passam a se realizar com representantes de vários segmentos sociais organizados, sendo a representação do segmento usuário de

\footnotetext{
${ }^{1}$ Doutora em Serviço Social pela UFPE, professora adjunta do Departamento de Serviço Social da UFSC. $\begin{array}{llllll}\text { Serviço Social \& Saúde } & \text { Campinas } & \text { v. } 6 & \text { n. } 6 & \text { p. } 1-170 & \text { Maio } 2007\end{array}$
} 
$50 \%$, de trabalhadores de saúde $25 \%$, de gestores públicos e prestadores filantrópicos e privados para o SUS $25 \%$.

O reconhecimento formal do espaço das Conferências e Conselhos na Lei 8.142/1990, ainda que represente certa acomodação dos interesses dentro da ordem, é resultado de um processo de luta de classes, onde havia disputa de direção ideo-política no período de redemocratização. É certo que nos anos de 1990 e início de 2000 este processo de luta de classes sofreu um refluxo significativo, mas ainda a meu ver, não é possível compartilhar com a visão de que se transformaram apenas em espaços de consenso e pactuação. Concordo com Bravo (2001, p. 47) que as Conferências são espaços tensos em que os diferentes interesses estão em disputa, devem ser visualizados como locus de fazer político, como espaço contraditório, como uma nova modalidade de participação, ou seja, a construção de uma cultura alicerçada nos pilares da democracia participativa.

Nestas duas décadas de vida do SUS as Conferências de Saúde estão representando uma socialização do debate político e estão abrindo canais à participação para segmentos sociais (trabalhadores rurais, indígenas, movimentos de mulheres, de negros, de deficientes e portadores de patologias) antes excluídos do debate sobre as decisões públicas e governamentais. Além disso, as Conferências representam uma caixa de reverberação ou babel político-ideológica, onde diferentes vozes políticas deixam marcas nas proposições que constam no Relatório Final.

As Conferências são espaços mais amplos de participação do que os Conselhos de Saúde, por serem mais informais e envolveram plenárias ascendentes nas três esferas de governo. Através das pré-conferências são mobilizados núcleos organizados desde a esfera inframunicipal que de outra forma teriam dificuldade de tomar conhecimento das pautas da saúde. Do lado da instituição, pode ser um espaço de

\begin{tabular}{llllll}
\hline Serviço Social \& Saúde & Campinas & v. 6 & n. 6 & p. $1-170$ & Maio 2007
\end{tabular}


participação dos servidores públicos, que quase sempre não dispõem de mecanismos para o encaminhamento de suas demandas e de diálogo com o próprio chefe. Por sua vez os prestadores privados de serviços para o SUS dão de cara com o povo anônimo da fila e da demanda reprimida. Entretanto, as plenárias também se configuram em espaços de manipulação, de reivindicações isoladas, de propostas consistentes e de experiências bem sucedidas. Ocorre também que as propostas resultantes do plenário, durante o processo de debate, de relatoria e de aprovação perdem um pouco de seu sentido original.

Nestes 16 anos de SUS, três momentos estão marcando sua trajetória e influenciando as Conferências e Conselhos, instrumentos privilegiados para a efetivação da diretriz constitucional de participação da comunidade: a) a implantação e a municipalização com desfinanciamento; b) a implosão de regulamentações e de programas focais; e c) o aumento das expectativas democráticas seguida de repentinas frustrações. Estes momentos possuem uma marca comum: o determinismo economicista que concebe o reconhecimento dos direitos sociais e de saúde apenas como mais um item do orçamento.

Nesta conjuntura contraditória em termos de reconhecimento e efetivação dos direitos à saúde, a prática da descentralização participativa é um ingrediente a mais, que por si só confere mais complexidade. A realização das Conferências de Saúde nas três esferas de governo é um dos instrumentos formais desta diretriz constitucional que inova e promete democracia, mesmo que nos limites da ordem burguesa.

No entanto, a forma e os ganhos democráticos dos debates realizados nestes espaços colegiados vem sendo questionados em termos das dificuldades de se garantir as diretrizes e os princípios do SUS. O neoliberalismo e o processo de reforma do Estado dos anos de 1990 são apontados como principais agentes limitadores da

\begin{tabular}{llllll}
\hline Serviço Social \& Saúde & Campinas & v. 6 & n. 6 & p. $1-170$ & Maio 2007
\end{tabular}


efetivação dos ganhos democráticos e dos direitos sociais conquistados na década de 1980.

\section{$12^{\circ}$ CONFERÊNCIA NACIONAL DE SAÚDE: O SUS QUE QUEREMOS?}

Com a intenção de avaliar estes ganhos democráticos, realizamos durante a $12^{\text {a }}$ Conferência Nacional de Saúde, uma pesquisa, com objetivo de conhecer os pontos positivos e negativos que os seus participantes identificavam na realização destas plenárias.

A $12^{\mathrm{a}}$ Conferência Nacional de Saúde realizou-se por convocação extraordinária, com antecipação de um ano em relação ao prazo regulamentar (Lei 8.142/90). Devido à posse do governo Luis Inácio Lula da Silva, esta Conferência se situou, pelo menos no âmbito da intencionalidade, num contexto de ampliação das regras formais da democracia, após a eleição de um presidente vindo de setores não burgueses da nossa sociedade.

Esta Conferência aconteceu em Brasília, em dezembro de 2003, e contou com a participação de 3.000 delegados nacionais, 300 observadores e mais de uma centena de membros da comissão organizadora e de relatoria. A $12^{\mathrm{a}}$ Conferência, também chamada de Conferência Sérgio Arouca ${ }^{2}$, teve como tema central: Saúde: um direito de todos e dever do Estado - a saúde que temos, o SUS que queremos. Os debates desta plenária foram divididos em dez eixos temáticos escolhidos pelo Conselho Nacional de Saúde ${ }^{3}$

\footnotetext{
${ }^{2}$ Sérgio Arouca além de ser um dos precursores da Reforma Sanitária, foi o coordenador da $8^{\mathrm{a}}$ e havia sido indicado para ser o coordenador da $12^{\mathrm{a}}$, mas em seguida adoeceu vindo a falecer em agosto de 2003. ${ }^{3}$ Direito à Saúde, à Seguridade Social e à Saúde; à Intersetorialidade das Ações de Saúde; às três Esferas de Governo e à Construção do SUS; a Organização da Atenção à Saúde; Gestão Participativa; o Trabalho na Saúde; Ciência e Tecnologia e a Saúde; o Financiamento da Saúde e Informação e Comunicação em Saúde.

$\begin{array}{llllll}\text { Serviço Social \& Saúde } & \text { Campinas } & \text { v. } 6 & \text { n. } 6 & \text { p. } 1-170 & \text { Maio } 2007\end{array}$
}


Esta foi a Conferência que mais mobilizou desde núcleos infra-municipais, passando pela realização de 3.640 Conferências Municipais e Estaduais, envolvendo cerca de 100 mil pessoas (Brasil, 2004). Como a $8^{\text {a }}$. Conferência, em 1986, no auge do período da redemcoratização, foi um evento de ruptura com a lógica, a forma e o conteúdo das anteriores, se tornou o principal evento vocalizador e consagrador das bandeiras da Reforma Sanitária. A $8^{\text {a }}$ foi perpassada, segundo Sérgio Arouca (2002, apud Machado, 2003:8), por um projeto civilizatório. Com a intenção de recuperar o espírito da época, em 2003 a expectativa dos organizadores da $12^{\mathrm{a}}$ Conferência era de que ela se tornasse um marco para as políticas de saúde como foi a $8^{\mathrm{a}}$. Conforme Noronha (2003, p. 10), os esforços foram para que a $12^{\mathrm{a}}$ revivesse, "em alguma medida, o espírito verdadeiramente democrático da inesquecível Oitava, momento consagrador da Reforma Sanitária brasileira e fundador do SUS".

Os 100 grupos de trabalho da Conferência apresentaram cerca de 4 mil emendas as 712 proposições do consolidado das etapas Estaduais, estas foram trabalhadas pela equipe de relatoria e após apreciação do plenário resultou um Relatório Final com 723 proposições ${ }^{4}$. No entanto, a pretensão da Comissão organizadora era produzir um Relatório enxuto e com proposições claras e objetivas para direcionar a política de saúde do governo que estava se iniciando. Expectativa que saiu frustrada em função da quantidade de proposições que se repetem e são detalhistas em demasia, ao mesmo tempo em que o Relatório Final demorou 11 meses para ser concluído.

\footnotetext{
${ }^{4}$ Número de proposições da $12^{\mathrm{a}}$ Conferência por eixo temático: 1 - Direito à saúde 44,2 - A Seguridade Social e a saúde 54, 3 - A intersetorialidade das ações de saúde 80,4 - As três esferas de governo e a construção do SUS 38, 5 - A organização da atenção à saúde 107, 6 - Controle social e gestão participativa 54, 7 - O trabalho na saúde 104, 8 - Ciência e tecnologia e a saúde 70, 9 - O financiamento da saúde 81, 10 - Comunicação e Informação 91. O processamento das propostas foi todo informatizado. O sistema permitiu a alimentação, indexação e agrupamento das propostas. Por exemplo, no consolidado das plenárias estaduais poderia se acessar a redação original das proposições que foram agrupadas na perspectiva de síntese.

\begin{tabular}{llllll}
\hline Serviço Social \& Saúde & Campinas & v. 6 & n. 6 & p. $1-170$ & Maio 2007
\end{tabular}
}


Durante a Conferência com formulário de questões abertas foram entrevistados aleatoriamente 137 participantes, dos quais 121 eram delegados, 6 observadores e 10 outros. Destes 54\% eram usuários, 14\% gestores, $11 \%$ trabalhadores, $5 \%$ prestadores e $16 \%$ com segmento ignorado. Ainda que o formulário tenha sido entregue em mãos ao entrevistado, com consulta sobre seu interesse e disponibilidade de responder, é importante salientar que o segmento usuário foi o mais receptivo e o segmento dos prestadores o mais resistente.

Sobre a participação dos entrevistados nos Conselho e Conferência de Saúde, temos o seguinte perfil. Dos entrevistadores $63,5 \%$ revelaram já terem sido ou são conselheiros de saúde com mandato de titular. Destes $27,7 \%$ com um mandato e $21,8 \%$ com 2 mandatos. Sobre a participação dos entrevistados em Conferência Nacional de Saúde 74,9 \% responderam já terem participado de uma Conferência Nacional ou que estavam na primeira participação, 10,9\% afirmaram já terem participado de duas e 9,4\% responderam que já participaram de três. Sobre a participação em Conferências Estaduais $54,7 \%$ dos entrevistados participaram de uma e $20,4 \%$ de duas. Em Conferências Municipais 37,3\% já participaram de uma, 19,7\% de duas e 18,9 de três.

Quanto o objeto deste texto, a análise dos pontos positivos e negativos para a implementação do SUS obtivemos dos entrevistados as seguintes respostas. Vale ressaltar como as respostas foram abertas, procuramos agrupar as respostas por afinidade.

Como pontos positivos $39 \%$ dos participantes indicaram a ampliação da participação popular no debate da política de saúde; $22 \%$ apontaram o fortalecimento da cidadania, da democracia e a consciência dos direitos; $13 \%$ o fortalecimento do controle social; $6 \%$ a avaliação do SUS; $4,5 \%$ a discussão sobre o financiamento do SUS e defesa da universalidade e do acesso, 4,5\% o intercâmbio e conhecimento da

\begin{tabular}{llllll}
\hline Serviço Social \& Saúde & Campinas & v. 6 & n. 6 & p. $1-170$ & Maio 2007
\end{tabular}


necessidade de outras regiões do país e de outros setores do SUS e 8,7\% não responderam. Vale destacar ainda outros pontos positivos que tiveram menor expressão no conjunto das respostas: aprovar melhorias para a saúde, a participação de todo país, possibilidades dos usuários participarem e escolherem e a apresentação das idéias divergentes para a melhoria da saúde.

De forma geral o debate político, a literatura e a legislação apontam como papel das Conferências o que os entrevistados evidenciaram que está se realizando nestes espaços. No entanto, um dos papéis importantes da plenária que é avaliar o SUS teve reconhecimento de apenas $6 \%$ dos entrevistados, enquanto o papel propositivo das políticas de saúde, apesar de ficar subentendido na maioria das respostas não foi mencionado. A valorização da participação social, o aumento dos espaços de democratização e de cidadania são reconhecimentos de que a Conferência de Saúde pode ser mais um espaço para socialização do debate das decisões públicas.

Como pontos negativos das Conferências Nacionais de Saúde 25\% dos entrevistados apontaram a não efetivação das propostas e a não incorporação nos Planos de Saúde nas três esferas de governo; 19\% a falta de objetividade do debate, a falta de entendimento do assunto e de compromisso dos integrantes da plenária; $18 \%$ indicaram como ponto negativo a existência da defesa de interesses próprios e manipulação político-partidária; $8,7 \%$ pouca participação popular e controle social ineficiente, 5,5\% que os gestores tem pouca participação e que ignoram o Relatório Final; 5\% a mesmice das propostas, conclusões e discussões pontuais e 5\% que o problema da Conferência está no não cumprimento da legislação. Outros pontos negativos de menor representatividade: falta de organização e educação dos participantes, falta de interesse político dos usuários, falta de organização dos participantes, autoritarismo, 
manipulação, vaidades, organizações populares débeis, conclusões e propostas vagas e visão de controle social restrita a estados e municípios.

Neste espaço de debate com interesses muito variados se considerarmos apenas os quatro segmentos que formalmente possuem constituem a Conferência percebe-se que este é um espaço de educação política, de aprendizado para tomada de decisões coletivas, dado a nossa história de exclusão dos setores populares os debates sobre as decisões do poder público. No entanto, quando se considera a origem de classe destes segmentos, que em nossa sociedade são representantes dos capitalistas e da classe trabalhadora a possibilidade de gerar consensos e pactos verdadeiros são remotas.

A maioria dos integrantes da plenária vem da classe trabalhadora, representando entidades ou movimentos sociais que normalmente pautam suas lutas pelas necessidades imediatas e/ou corporativas. Assim podemos perceber que reproduzem este comportamento na Conferência. Tal situação ficou bastante evidenciada nos pontos negativos apontados pelos participantes com as referências a defesa de interesses particulares, autoritarismo, manipulação e pouco controle social.

São inegáveis os avanços democráticos, o aumento da consciência política e a defesa do SUS identificados nos pontos positivos, mas é visível nas respostas dadas que falta um posicionamento majoritário da plenária em defesa de como desejam que o SUS seja concretizado.

Não podemos pensar a realização de uma Conferência de Saúde deste porte isenta de conflitos e contradições, mas a potencialização e destes conflitos e contradições são aumentadas pela falta de clareza, de dispersão e direção política (frágil cultura política) dos segmentos que são a maioria na plenária: usuários e profissionais de saúde. De outro lado, os representantes dos gestores públicos e privados, normalmente identificados como representantes do capital, possuem dificuldade de

\begin{tabular}{llllll}
\hline Serviço Social \& Saúde & Campinas & v. 6 & n. 6 & p. $1-170$ & Maio 2007
\end{tabular}


aprovar suas propostas em plenário por não serem maioria, pelas respostas dos pontos positivos e negativos, considera-se que apresentam nas plenárias um comportamento de neutralização, isenção ou de cooptação. E como estes tem poder de implementação do SUS, dependendo da perspectiva política, podem fazer a gestão a revelia das proposições das Conferências de Saúde.

Com estes resultados avaliamos que as Conferências estão se tornando espaços em que a sociedade civil pode interferir na direção das decisões da gestão pública, bem como facilitam a interlocução e a demonstração das necessidades dos vários segmentos sociais. Reconhecendo a dimensão continental do país a Conferência possibilita que os participantes conheçam e debatam as necessidades regionais. No entanto, esta democratização do debate da saúde não está isento de contradições, pois as decisões coletivas decorrentes das Conferências estão sendo ignoradas pelos gestores no momento de fazer os Planos e decidir sobre as ações. Também se reconhece elementos tradicionais da nossa cultura política se reproduzindo, como os interesses partidários, o individualismo e o não cumprimento da legislação.

\begin{abstract}
This text presents and analyzes the results of a research carried out in the 12th National Health Convention, in 2003, with the objective of knowing the positive and negative that its participants identified when taking part of the plenary sessions. The health conferences have been known as a wide space for democratization of the health area because of its task of evaluating and making propositions for bringing the health politic to execution. During these two decades of life from SUS the health conferences are formally representing a socialization of the political debate and are opening channels for the participation of social segments which were previously excluded from the debate about the public and governmental decisions. However, the results of this study show that the gains are partial and contradictory.
\end{abstract}

\begin{tabular}{|c|c|c|c|}
\hline Serviço Social \& Saúde & Campinas & v. 6 & n. 6 \\
\hline
\end{tabular}


KEYWORDS: SUS; Health Conference; Social Control and Political Socialization.

\section{REFERÊNCIAS BIBLIOGRÁFICAS}

BRASIL. Lei n. 8.142 de 28 de dez. de 1990. Dispõe sobre a participação na comunidade na gestão no Sistema Único de Saúde - SUS - e sobre as transferências intergovernamentais de recursos financeiros na área da saúde e dá outras providências. BRASIL. 12 ${ }^{a}$. Conferência Nacional de Saúde: Conferência Sérgio Arouca: Manual: Brasília, 07 a 11 de dezembro de 2003.

BRASIL. Relatório Final da $12^{a}$. Conferência Nacional de Saúde. Brasília: Ministério da Saúde. 2004.

BRAVO, M. I. Gestão democrática na saúde: o potencial dos conselhos. In. Política social e democracia. São Paulo: Cortez, 2001.

HISTÓRIA DAS CONFERÊNCIAS NACIONAIS DE SAÚDE. $<$ http://www.fiocruz.br/ > acesso em 27 out. 2002.

KRÜGER, T. R. Os fundamentos ideo-políticos das Conferências Nacionais de Saúde. Recife: PGSS/CCSA/UFPE, 2005.

MACHADO, K. A saúde que queremos.... Rio de Janeiro: Manguinhos/Fiocruz, n. 16, dez.2003.

NORONHA, A. B. $12^{\text {a }}$ CNS: mudando para melhor. RADIS Comunicação e Saúde. Rio de Janeiro: Fiocruz, nov./2003, n.15. 